\title{
IMPACT OF ANNAPURNA KRISHI PRASARA SEVA (AKPS) AGRO ADVISORY \\ SERVICES IN EAST COASTAL DISTRICTS OF ANDHRA PRADESH
}

\author{
BANDARU LAKSHMI SOWJANYA ${ }^{1}$, P. K. BANERJEE ${ }^{2}$, \\ P. PUNNARAO ${ }^{3} \&$ T. S. ANURAG ${ }^{4}$
}

${ }^{I}$ Research Scholar, Department of Extension Education, Orissa University of Agriculture and

Technology, Bhubaneswar, India

${ }^{2}$ Associate Professor, Department of Extension Education, Orissa University of Agriculture and

Technology, Bhubaneswar, India

${ }^{3}$ Principal, Agricultural Information Officer, Acharya N G Ranga Agricultural University,

Guntur, Andhra pradesh, India

${ }^{4}$ Principal and Research Scientist, Digital India Corporation (Formerly Media lab Asia), New Delhi, India

\section{ABSTRACT}

Interactive Information Dissemination system (IIDS) framework has been pilot tested as ANNAPURNA KRISHI PRASRASA SEVA in 2013 which is currently expanded to 3350 mandals and 663 districts of Andhra Pradesh and Telangana to provide need-based information to the register farmers on multi-disciplinary aspects. Both purposive and random sampling methods followed for drawing a sample of one hundred and twenty from Vizianagaram and Srikakulam districts.

The findings of the study revealed that majority of the beneficiary farmers were of middle-aged (61.66\%), illiterate (34.16 \%) and farming as major occupation (45\%), belonged small farmers to medium category (35\%), 10-25 years of experience (62.50\%), medium economic status (83.33\%), no membership (76.66\%), low extension contact (54.16\%), medium level of scientific orientation (79.16\%), low mass media exposure (50\%) and medium level of innovativeness (70.83\%). The Majority of the respondents have moderately favorable attitude (44.16\%) towards Akps agro advisory service where the messages were partially understandable (41.66\%), needful (83.33\%), timely (53.33\%), saves time\& money (83.33\%), increase in knowledge (79.16\%), increase productivity (83.33\%), information can be adoptable in field conditions (43.33\%), AKPS is a boon to the farming community (60.83\%). Occupation, annual income, social participation, scientific orientation, innovativeness, mass media exposure shows a significant relationship with the impact of AKPS Services whereas Age, education, landholding and farming experience were found nonsignificant. Hence, by enhancing relevance to the location-specific field conditions through proper infrastructural facilities through advanced technology even to the remote areas can cater desirable impact on the beneficiaries in order to expand the services.

KEYWORDS: IIDS, AKPS Agro Advisory Services, Profile Characteristics \& Impact of AKPS Services

Received: Jun 21, 2018; Accepted: Jul 12, 2018; Published: Jul 26, 2018; Paper Id.: IJASRAUG20187

\section{INTRODUCTION}

Indian farming being mostly subsistence in nature, where farming community is confronted with the parcel of issues in amplifying the yield of efficiency. Mobile phones had changed the scenario of communication. 
Mobile usage has enabled the farming community to access agriculture and other business information reducing cost, time and money.

The farming community has a heap of issues in maximizing the crop productivity; inspire of prosperous research/technology on new agricultural practices the majority of farmers not getting proper information due to several reasons as information plays a critical role at every stage of action. However, the introduction of information and communication technologies (ICT) in the field of agriculture has brought several changes in ancient strategies of methods of extension.

Accordingly, IIDS was designed to address the techno-managerial communication dissemination gap between research and farming system by enhancing focus on technology gestalt to develop a commingle system that is capable of providing need-based information to the farmers IIDS is a combination or small phone application, interactive portal and IVRS

IIDS Framework has been pilot tested as Annapurna Krishi Prasara Seva in Andhra pradesh and m4agriNEI in Imphal during, 2013 and AKPS currently expanded to all the districts covering 3350 mandals and 663 districts of Andhra Pradesh and Telangana through KVKs/DAATTC/RARS of ANGRAU and PJTSAU.

Agri-experts would provide personalized solution in the form of voice and text messages and calls based on the input provided by the registered farmers on Multi-disciplinary aspects like weather- based agro advisories, precautionary measures, control measures for pests and diseases in rice, animal husbandry (Dairy) and fisheries, market information, seed availability and other subsidiary schemes.

Keeping this in view in order to render vehement, rationalized information related to actual circumstances, the present study entitled "Impact of Anna Purna Krishi Prasara Seva (AKPS) Agro advisory services in East coastal Districts of Andhra Pradesh" was been undertaken with the following objectives: -

- To study the Socio economical and communication profile of the respondents.

- To assess the impact of Annapurna Krishi Prasara Seva on the beneficiaries.

- $\quad$ To find out the relationship between profile characteristics and Impact of AKPS Services.

\section{METHODOLOGY}

The study was conducted with registered farmers in Srikakulam and Vizianagaram districts of Andhra pradesh. A sample of 120 was taken with purposive and random sampling procedures for the study. Ex-Post facto research Design was followed using a structured interview schedule. A primary source of the data was collected from the registered farmers and secondary data was incorporated from the AKPS official records of KVK-SRIKAKULAM and DAATTC-VZM, journals, thesis, internet. The Statistical tools frequency, percentage, mean, class interval and person's coefficient of correlation. Ten registered farmers from each mandal were selected through random sampling whereas 2 districts and 12 mandals (6 from each district) selected purposively comprising a total number of 120 respondents formed from the sample for the study. After conducting a pilot study asper 5 per cent of the respondents were personally interviewed for the purpose of pretesting of the interview schedule for its reliability \& validity and after necessary modifications, the final schedule was developed for eliciting responses from the farmers. 


\section{RESULTS AND DISCUSSIONS}

Salient features of the study are as follows

\section{Profile of the Respondents}

Age

Majority of the respondents were middle-aged (61.66\%), followed by young $20 \%$ ) followed by old age group $(18.33 \%)$.

It was concluded that majority of the respondents $61.66 \%$ were middle-aged, having quite passionate, and are enthusiastic and have more working efficiency than older and younger ones. This might have influenced their decisions and to have active participation in AKPS agro advisory services.

\section{Education}

Majority of the respondents were Illiterate (34.16\%) followed by followed by only read and write (17.50\%), high school $(15.83 \%)$, primary school $(12.50 \%)$, higher secondary $(10.83 \%)$ and graduation and above $(11 \%$.

As far as education is concerned, maximum percentage of the respondents were illiterate (34.16\%). It can be said that the educational status of the respondents was not satisfactory. This might lead to low interactive information dissemination. Because of low level of education AKPS services are also accessible in voice message form.

\section{Occupation}

Majority $45 \%$ of the respondents were involved in farming followed by (25\%) involved in farming along with business, $(20 \%)$ involved in farming along with service and (8\%)of the respondents were involved in farming along with business and service and (4\%) of the respondents are involved in other activities.

It was concluded that the area is predominated by agriculture \&allied farming activities and is the main source of their livelihood so the AKPS services are confined to agriculture and allied farming activities only.

\section{Annual Income}

Majority $83.33 \%$ of the respondents belonged to medium economic status followed by 10 per cent belong to high economic status and the remaining 6.66 per cent belong to low economic status

With respect to annual income, the majority of the respondents $(83.33 \%)$ belonged to the medium income group (Rs.25000-Rs.75000). The possible reason may be that most of the respondents were having a small and medium size of land holding. This may be attributed for farming background of the respondents to cater with the AKPS availing services

\section{Land Holding}

Majority $35 \%$ of the respondents had to small size of the landholding followed by 25 per cent medium size of the landholding and 20.83 per cent had to marginal size of the landholding and the remaining $19.16 \%$ of respondents had larger size of landholding.

Possession of small size of the landholding, might be due to continuous fragmentation of the land from generation to generation among brothers 


\section{Farming Experience}

The majority (62.50\%) of the respondents had 10 to 25 years of experience followed by (20.83\%) having Up to 10 years of experience and the remaining $(16.66 \%)$ had more than 25 years of experience

With respect to farming experience majority $(62.50 \%)$ of the respondents were middle-aged and might have satisfactory experience helps in better understanding of the AKPS services for resolving their diverse problems in agriculture and allied activities

\section{Social Participation}

The majority $(76.66 \%)$ of the respondents were neither members nor office-bearers of any social organization and the remaining 23.33 per cent of the respondents having membership in social organizations.

With respect to the social participation majority $(76.66 \%)$ of the respondents were neither members nor officebearers of any social organization due to lack of interest which instigate to dearth awareness about the activities in social organizations.

\section{Scientific Orientation}

Majority $79.16 \%$ of the respondents were medium scientific oriented followed by $16.66 \%$ low scientific oriented and the remaining 4.16 per cent were high scientific oriented.

Thus, it can be concluded that a higher percentage of respondents had the medium level of scientific orientation. Hence, by adopting the information provided by the AKPS services in the field conditions can reduce the level of uncertainty in agriculture and allied activities

\section{Innovativeness}

It was discernible from the Table that majority $70.83 \%$ of the respondents had a medium level of innovation followed by 20 per cent have a low level and the remaining 9.16 percent have the high level of innovativeness

Thus it can be concluded that a higher percentage of the respondents had the medium level of innovativeness as it depends upon many factors like education, occupation, annual income, land holding, farming experience and social participation. In this investigation, the majority of the respondents belonged to medium level of innovativeness might be due to the factors like medium annual income, small land holding, medium farming experience and low social participation which instigate to their innovativeness.

\section{Mass Media Exposure}

Majority (41.66 \%) of the respondents have a medium level of Mass media exposure followed by 33.33 per cent having low mass media exposure and the remaining $25 \%$ having high mass media exposure.

Thus it can be concluded that majority of the respondents belonged to the medium level of mass media exposure. Hence, by strengthening awareness through need-based training on mobile based agro advisory services through mass media exhibit considerable impact and can bring more and more beneficiaries under AKPS based agro advisory services. 


\section{Extension Contact}

It was discernible from the Table that majority $(54.16 \%)$ of the respondents have low-level extension contact followed by 41.66 per cent having medium mass media exposure and the remaining 4.16 per cent having high extension contact.

Thus it can be concluded that majority (54.16\%)of the respondents belonged to low extension contact due to lack of interest in participation of extension activities Hence, by strengthening practical exposure and training towards mobilebased agro advisory services can create interest and bring more and more beneficiaries under AKPS based agro advisory services.

\section{IMPACT OF ANNAPURNA KRISHI PRASARA SEVA (AKPS)}

\section{Understanding of the Message}

The ability of the respondent to comprehend the message delivered through Annapurna Krishi Prasara Seva (AKPS) service is collected, analyzed and presented messages were partially to highly understandable by respondents. Majority (41.66\%) had opined understandability of AKPS messages followed by $33.33 \%$ opined for higher understandability and 25\% respondents stated that AKPS messages are not understandable.

Thus it can be concluded that majority of the respondents belong partial understanding of the message promotes erudition relevance to field conditions.

\section{Need Based Information}

Need is a condition or situation in which something must be supplied in order for a certain condition to be maintained or a desired state to be achieved through Annapurna Krishi Prasara seva. In this regard, responses were collected and presented that information was needful for $83.33 \%$ of the respondents followed by sum what needful $10 \%$ and the remaining not needful for $6.66 \%$ of the respondents it was no needful.

Thus it can be concluded that information provided by the APKS Services is needful for the majority of the respondents to the extent to which it is needed by them.

\section{Time-Based Information}

Timely information is very important for farmers to be aware about various agricultural activities Through Annapurna Krishi Prasara seva. In the context, the responses collected and presented that majority 53.33\% of the respondents agree that messages were timelyfollowed by $41.66 \%$ undecided about the timeliness of the information and the remaining $6.66 \%$ of the respondents reported that messages were not timely.

Thus it can be concluded that APKS Services providing the right information at right time for $53.3 \%$ of the respondents which will ensure the farmers to carry out their activities in a planned manner and can achieve best benefits from it but this needs to be expanded for other farming communities also.

\section{Saves Time and Money}

Time and money are the important factors for the farmers while performing agricultural operations. Information on savage of Time and money through Annapurna krishi prasara seva service. In this regard nearly, majority $83.33 \%$ of the respondent agreed that information delivered through AKPS service saves time and money followed by $10 \%$ were 
undecided and the remaining $6.66 \%$ reported that information is not enough to save time and money

Thus it can be concluded that information provided by the APKS Services saves time and money for the majority of the respondent.

\section{Increase in Social Contact}

Social contact refers to sociological hierarchy leading up to social relations, an incidental social interaction between individuals. Information on the increase in social contact through Annapurna krishi prasara seva service (AKPS). In this regard nearly, majority $79.16 \%$ of the respondent agree that information delivered through AKPS service promote an increase in social contact of the respondents followed by $16.60 \%$ were undecided and the remaining $4.16 \%$ reported that information is not enough to an individual's interaction with the group relationships beyond the households.

Thus it can be concluded that information provided by the APKS Services promote an increase in social contact for the majority of the respondents.

\section{Increase in Knowledge}

Information on the increase in knowledge through Annapurna krishi prasara seva service(AKPS) from majority $83.33 \%$ of the respondent agree that information delivered through AKPS service provide an increase in knowledge followed by $9.16 \%$ were undecided and the remaining $7.50 \%$ reported that information is not enough to increase knowledge.

Thus it can be concluded that information provided by the APKS Services helped to increase knowledge for the majority of the respondents.

\section{Increase in Productivity}

Information on the increase in productivity through Annapurna krishi prasara seva service from majority $66.66 \%$ of the respondent agree that information delivered through AKPS service provide an increase in productivity followed by $18.33 \%$ undecided and the remaining $15.00 \%$ reported that information is not enough to help increase the productivity.

Thus it can be concluded that information provided by the APKS Services helped in increasing in productivity for the respondents.

\section{Adoptability in Field Conditions}

Information on adoptability of AKPS services in field conditions from majority $43.33 \%$ of the respondent agreed that information delivered through AKPS service can be adoptable in field conditions followed by $29.16 \%$, who opined for partial adoptability and the remaining $27.50 \%$ reported that information is not enough to be adopted in field conditions

Thus it can be concluded that information provided by the APKS Services can be adoptable in the field conditions for the respondents to the extent to which it is needed by them.

\section{AKPS is a Boon to the Welfare of the Farming Community}

Information on Annapurna krishi prasara seva service(AKPS) is a boon to the welfare of the farming community that majority $60.83 \%$ of the respondent agreed that AKPS service is a boon to the welfare of the nation followed by $29.16 \%$ who were undecided and the remaining $10 \%$ disagreed with the statement. 
Thus it can be concluded that information provided by the APKS Services is a boon to the welfare of the farming community.

\section{Overall Impact of the Respondents towards AKPS Agro Advisory Services}

An overall score on individual impact of each parameter on AKPS was arrived by summing up the scores of the nine components based on maximum and minimum values obtained. It is grouped into 3 categories and presented in the table 4.3.1.10

Table 1: Distribution of Respondents According to Overall Impact Level towards AKPS Agro Advisory Services (N=120)

\begin{tabular}{|c|c|c|c|}
\hline Categories & Score Range & Frequency & $\%$ \\
\hline Low & $9-15$ & 18 & 15.00 \\
\hline Medium & $15-21$ & 80 & 66.66 \\
\hline High & $21-27$ & 22 & 18.33 \\
\hline & 120 & 100.00 \\
\hline
\end{tabular}

It was discernible from the Table that majority $66.66 \%$ of the respondents had reported for medium impact on AKPS Services followed $18.33 \%$ had high impact and the remaining $15 \%$ had a low impact towards AKPS agro advisory services.

Thus it can be concluded that majority of the respondents have the medium level of impact towards AKPS Agro advisory service. Hence, by enhancing relevance to the location-specific field conditions through proper infrastructural facilities using advanced technology even to the remote areas can have a desirable impact on the beneficiaries in order to expand the services. The results were in line with Punnarao, P. et al., (2017).

\section{RELATIONSHIP BETWEEN PROFILE CHARACTERS AND IMPACT OF AKPS SERVICES}

In order to study the relationship profile characteristics with the impact of AKPS Services, the correlation was employed.

\section{Null Hypothesis}

There is no significant relationship between selected profile characteristics and impact of AKPS Services and both of these are independent.

\section{Relationship between Profile Characteristics and Impact of AKPS Services}

Table 2: Relationship between Profile Characteristics and Impact of AKPS Services $(n=120)$

\begin{tabular}{|l|c|}
\hline \multicolumn{1}{|c|}{ Characteristic } & Correlation Coefficient " $\mathbf{~}$ " \\
\hline Age & $.002 \mathrm{~N}$ \\
\hline Education &. $.068 \mathrm{~N}$ \\
\hline Occupation & $.264^{*}$ \\
\hline Annual income & $.313^{* *}$ \\
\hline Land holding & $.132 \mathrm{~N}$ \\
\hline Farming experience & $.052 \mathrm{~N}$ \\
\hline Social participation & $.305^{* *}$ \\
\hline Scientific orientation & $.647^{* *}$ \\
\hline Innovativeness & $.340^{* *}$ \\
\hline Mass media exposure & $-.070^{* *}$ \\
\hline
\end{tabular}




\begin{tabular}{|l|c|}
\hline \multicolumn{2}{|c|}{ Table 2: Contd., } \\
\hline Extension contact & $.251^{*}$ \\
\hline
\end{tabular}

*Significant at $5 \%$ level

**Significant at $1 \%$ level

$\mathrm{N}$-Non significant

The data revealed that, occupation, annual income, social participation, Scientific orientation, innovativeness, mass media exposure and extension contact were found positively and significantly related with the impact of AKPS Services indicating positive and significant relationship with the impact of AKPS services, whereas Mass media exposure was found negatively significant relationship with the impact of AKPS Services.

Whereas age, landholding and farming experience were positively and non-significantly correlated with the impact of AKPS services and education was negatively non-significant with the impact of AKPS Services. The results were in line Kabir, K. H. (2015)

\section{CONCLUSIONS}

The Study indicate that AKPS is one of the most useful tools of ict for dissemination of agricultural information to the registered farmers and can play a greater role in enhancing efficiency of extension services by reaching a large number of people results of the study showed that AKPS Agro advisory services had medium level of impact on the registered farmers and confessed the messages were partially understandable, needful, timely, saves time and money, increase social contact, knowledge and increase productivity, and information provided by AKPS is adoptable in field conditions and serves as a boon to the welfare of the farming community

Hence, by enhancing relevance to the location-specific field conditions through proper infrastructural facilities through advanced technology even to the remote areas can cater desirable impact on the beneficiaries in order to expand the services.

\section{REFERENCES}

1. Ansari, A. and Pandey, N. 2013. Assessing the potential and use of mobile phone in agriculture, Karnataka j. Agri. sci.26 (3):388- 392 .

2. Chavhan, P. N., Deshmukh, P. R and Aglawe, D. D. 2018. Constrains faced and Suggestions provided during the use of mobilr based agro advisory services by state department of agriculture in Marathwada region, International journal of chemical science,6(3): 1715-1719.

3. Devraja, S. C. 2011. A Study on Knowledge and attitude of the farmers using ICT tools for farm communication, M. Sc. (Ag.) thesis, GVKV, Bengaluru.

4. Guha, Subhanil, and Anindita Dey. "Coastal Morphological Dynamics Of Nayachara Island Using Geoinformatics."

5. Dhaka, L. and Chayal, K. 2010. Farmers experience with ICT's on transfer of technology in changing agricultural rural environment, Indian research journal of Extension Education, 10 (3):114-18.

6. Patra, J., Singh, D. V. and Pati, J. K. 2016. Kisan mobile advisory -an effective ict tool for technology dissemination, International Journal of Humanities and Social Science Invention, 5(6):68-72.

7. Punnarao, P., Reddy, K. J., Anurag, T. S., Mahadevaiah, M. And P Sailu, 2017. Interactive information dissemination system (IIDS) - An Alternative I. C. T model to meet the information needs of the farmers, Journal of Pharmacognosy and Phytochemistry, SPI: 314-318. 

Services in East Coastal Districts of Andhra Pradesh

8. Reddy, G., Rao, P., Mallika, M. and Aruna, S, I. 2011. Farmer's perception on usefulness of ICT initiatives in agriculture, Journal of Agricultural Extension Management, 12 (1):37-47.

9. Tomar, A., Bhardwaj, N., Verma, A. P., Sawant, M. N. 2016. Association between socio-demographic profile and extent of use of ICT among farmers, International journal of agricultural sciences and research, 6 (6):163-168. 
